\title{
An asynchronized synchronous machine to control a flexible grid operation
}

\author{
Igor S. Suprunov ${ }^{1, *}$, Dmitry V. Dvorkin ${ }^{1, *}$, Aleksander N. Novikov² and Nikolay L. Novikov ${ }^{2}$ \\ ${ }^{1}$ JSC “STC UPS Power system development”, Department of System Development, 109074, Moscow ,Kitaygorodskiy pass., 7, b.3. \\ Russia. \\ ${ }^{2}$ PJSC «FGC UES», 117630, Moscow, Akademika Chelomeya str., b.5A; «MPEI», 111250, Moscow, Krasnokazarmennaya 14; «JIHT \\ RAS», 125412, Moscow, Izhorskaya st. 13 Bd.2. Russia.
}

\begin{abstract}
In this paper, a system of two asynchronized synchronous machines is proposed to control a power-flow in a meshed grid of $220 / 500 \mathrm{kV}$ and a control algorithm, including a system parameterization guide. The proposed system is supposed to qualitatively affect the parameters of steady-state modes and shirtcircuit-caused transient processes and to increase the transfer capacity of the grid. Wherein, this double-fed synchronous machines complex allows for a significant increase in the power quality and reliability within the grid's normal operation. Long-term dynamics is considered. As a result, it is shown that the proposed system parametrization provides a significant decrease in active power fluctuations and power system swinging.
\end{abstract}

\section{Introduction}

The interconnection of large Power Grids (PG) causes significant power flows through the tie-lines caused by a wide range of reasons, such as ensuring system reliability, time zone effect, etc. [1-3]. At the same time, the comparative chaotic nature of the large consumption centers development within the $\boldsymbol{P G S}$ and various elements of the tie-line connections leads to the fact that at a certain moment the existing grid infrastructure becomes incapable of ensuring the normal grid operation with the given actual interconnection tie flows due to insufficient power transmission capacity [1$3,7-9,11-14,20-24]$. One of the ways to increase the power transmission capacity is the application of flexible grid technologies based on the Double-Fed Synchronous Machines Complex (DFSMC) [3,8, $9,10,17,18]$. This paper discusses the possibility of DFSMC application to increase the transmission capacity of the power grid and addresses the main technical and economic factors.

Since the flexible tie-line construction based on DFSMC requires high costs, therefore, for economic reasons, a combined solution is considered when DFSMC is installed in parallel with an autotransformer (AT) of comparable capacity instead of a traditional substation (S) with two ATs [17,30].

It is important to note that the contributions devoted to the DFSMC implementation for power transmission capacity increase have been previously published. So, in [32] it was proposed to use a current-limiting reactor connected in parallel with the DFSMC. The qualitative difference between the present paper and the aforementioned studies is that the latter examined the properties of flexible interconnection tie-line in steadystate operation modes using simplified $\boldsymbol{P} \boldsymbol{G}$ models. At the same time, the power generation equipment influence on the $\boldsymbol{P} \boldsymbol{G}$ operation modes, as well as the voltage level impact on the load static characteristics were not taken into account. Thus, the issues of the operation modes comprehensive study of such a two-component device in a complex power system in steady-state and transient electromechanical processes remained unresolved.

\subsection{Generalized model of DFSMC}

To create a flexible interconnection tie-line, a technical complex based on DFSMC was chosen since it allows $[3,4,8,11,12,25]$ :

- controlling the active power flow over a wide range;

- regulating the voltage and reactive power balance;

- providing complete electrical isolation of two large grid areas, limiting the short-circuit currents in-feeds and power quality distortions significantly;

- operating as an electric energy storage device.

The DFSMC is a controlled power device that includes two asynchronized synchronous machines $(\boldsymbol{A S M})$, the rotors of which are united by a common shaft, connected to a three-phase power source, static frequency converters supplying the DFSMC excitation, a field regulator and other auxiliary systems (Fig. 1) $[14,24,25,27-37]$. On the rotor of each of the machines, there are two symmetrically positioned field coils $d-d$ and $q-q$, which are powered from $\boldsymbol{P} \mathbf{1}$ and $\boldsymbol{P} \mathbf{2}$ by the alternating current with an $\omega$ frequency.

The rotation frequency of the rotor winding field $\omega_{\xi}$ is formed depending on the DFSMC shaft $\omega_{r}$ rotation speed and the orientation frequency $\omega_{r \xi}$, selected as the required frequency to ensure the $\boldsymbol{E} \boldsymbol{M} \boldsymbol{F}$ vector rotation $E_{\xi}$

\footnotetext{
* Corresponding authors: suprunov-is@ntc-msk.ru, dvorkin-dv@,so-ups.ru
} 
of each of the DFSMC machines (where $\xi=1,2$ corresponds to the subsystems numbers to which DFSMC machines are connected) [39]:

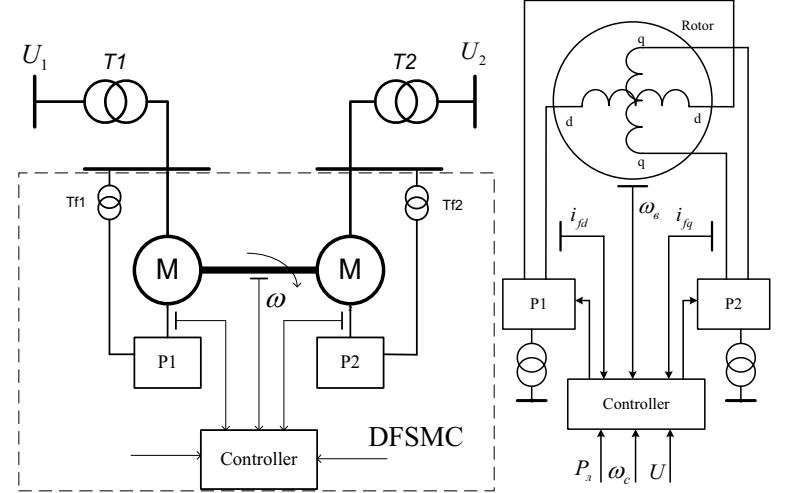

Fig.1. Principal scheme of $\boldsymbol{D F} \boldsymbol{F} \boldsymbol{M}$ and its excitation system

$$
\omega_{\xi}=\omega_{r \xi}-\omega_{r}
$$

In steady-state, the $\boldsymbol{E M F}$ rotation frequency $E_{\xi}$ is determined by the expression:

$$
\omega_{E \xi}=\omega_{r}+\omega_{\xi}
$$

Substituting expression (2) into (1), it can be seen that the $\boldsymbol{E M F}$ speed is determined according to the following law:

$$
\omega_{E \xi}=\omega_{r \xi} .
$$

Thus, the $\boldsymbol{E M F}$ speed is independent of the shaft speed $\omega_{r}$. The frequency $\omega_{r \xi}$ is taken equal to the frequency $\omega_{\xi}$ of the subsystem $\xi$, electrically coupled with the machine. By changing the module and the $\boldsymbol{E M F}$ $E_{\xi}$ phase by an automatic regulator, it is possible to implement the required $\boldsymbol{D F S M C}$ operation mode.

Since the magnetic flux in the rotor is formed as a result of two fluxes $d-d$ and $q-q$, which are created by the excitation currents $i_{f d}$ and $i_{f q}$, the rotor current corresponding to the resulting flux can be considered as a space vector in the rotor's own coordinate system $(d$, $q$ ), the coordinate axis of which ( $d$ axis) coincides with the $d-d$ winding axis, and the abscissa axis ( $q$ axis) - with the $q-q$ winding axis. It is assumed that the $d$-axis is imaginary and the $q$-axis is real. Then, the current in the field coil is determined according to the expression:

$$
\dot{I}_{f}=i_{f q}+j \cdot i_{f d} \text {. }
$$

In the given coordinates, the Park-Gorev equations take the following form:

$$
\left.\begin{array}{c}
-\dot{u}_{s}=\frac{1}{T} x_{s} \cdot \dot{i}_{s}+\left(p+j \omega_{r \xi}\right) \cdot\left(x_{s} \cdot \dot{i}_{s}+\dot{e}_{f}\right) \\
\dot{u}_{f}=\dot{e}_{f}+\left[p+j\left(\omega_{r \xi}-\omega_{r}\right)\right] \cdot\left(\mu \cdot x_{s} \dot{i}_{s}+\dot{e}_{f}\right) \cdot T_{f} \\
T_{f} \cdot p \omega_{r}=-\sum_{\xi=1}^{2} \operatorname{Re}\left(j \cdot \dot{e}_{f \xi} \hat{\imath}_{s \xi}\right)
\end{array}\right\}
$$

where $\dot{u}_{f}=x_{a f} \cdot \dot{u}_{f}^{e x c} / r_{f}$ is the reduced excitation voltage proportional to the voltage $\dot{u}_{f}^{\text {exc }}$, applied to the excitation field; $\dot{e}_{f}=x_{a f} \cdot \dot{i}_{f}$ is the reduced rotor current proportional to the current $\dot{i}_{f} ; T_{f}=x_{f} / r_{f}$ is the time constant of the rotor winding; $\mu=x_{a f}^{2} /\left(x_{s} \cdot x_{f}\right)$ is the magnetic coupling ratio between the stator and rotor windings; $T=x_{s} / r_{s}$ is the time constant of the stator winding.
The automatic field controller DFSMC provides harmonic variations of the control voltage $\dot{u}_{f}$ supplied to the field coils with the frequency $\omega_{f}$, i.e. changing its module and phase depending on the operation mode of the combined control device and adjacent subsystems. To ensure the vector $\boldsymbol{E M F}$ rotation $\dot{E}_{\xi}$ the excitation voltage $\dot{u}_{f \xi}$ is analytically determined according to the expression [25,39,41-44]:

$$
\dot{u}_{f \xi}^{(o r)}=u_{f \xi}^{\prime(o r)}+j u_{f \xi}^{\prime \prime}(\text { or }),
$$

or graphically as shown in Fig.2.

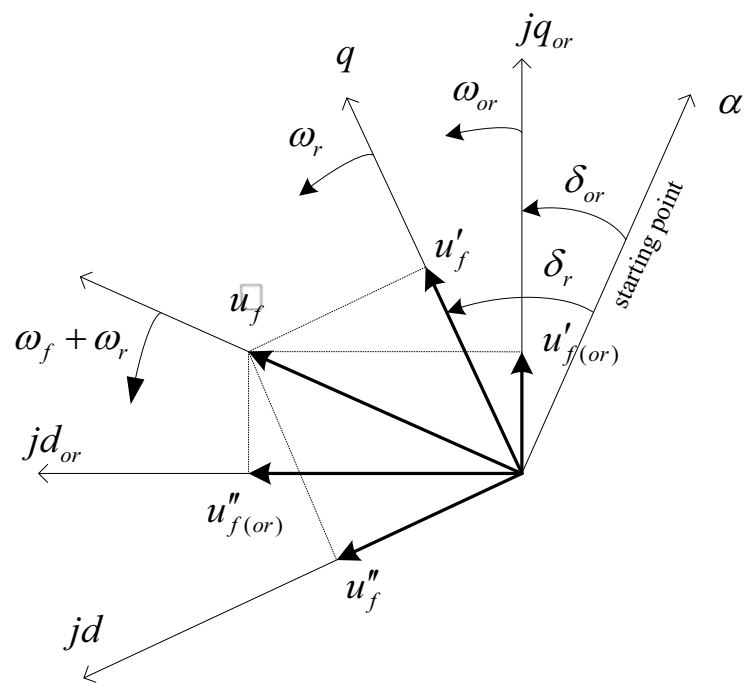

Fig.2. Vector $\dot{u}_{f}$ and its projections on $d_{o r}, q_{o r}$ and $d_{\xi}, q_{\xi}$ axis

A change in the module and phase of $\boldsymbol{E M F} \dot{E}_{\xi}$ is caused by a change in the excitation voltage $\dot{u}_{f y \xi}$, according to the following law:

$$
\left.\begin{array}{l}
u_{y \xi}^{\prime(o r)}=\alpha_{0}+\sum_{i} W_{i}(p) \cdot \Delta P_{i} \\
u_{y \xi}^{\prime \prime(o r)}=\beta_{0}+\sum_{j} W_{j}(p) \cdot \Delta P_{j}
\end{array}\right\}
$$

where $u_{y \xi}^{\prime(o r)}$ and $u_{y \xi}^{\prime \prime(o r)}$ are the control voltage projections on the $q_{o r}$ and $j d_{o r}$, respectively; $\alpha_{0}$ and $\beta_{0}$ are the steady state parameters; $W_{i}(p), W_{j}(p)$ are the transfer functions of the automatic excitation controller $(\boldsymbol{A E C})$ of $\boldsymbol{A S M} ; P_{i}, P_{j}$ are the parameters of the current operation mode.

The law or algorithm for the frequency $\omega_{f}$ calculation as a frequency function $\omega_{o r}$ of the selected orientation vector and the converter shaft $\omega_{r}$ rotation frequency is uniquely determined from the condition of ensuring the steady state mode given the shaft frequency $\omega_{r}$ different from the adjacent subsystem frequency $\omega_{\text {or }}$ $\left(\omega_{f}=\omega_{o r}-\omega_{r}\right)$.

To increase the power transmitted over the interconnection tie-line, the case of a DFSMC with $\boldsymbol{A T}$ connected in parallel was considered $[30,32,36]$. For the simplicity reasons the combined power flow controller with $\boldsymbol{D F S M C}$ and $\boldsymbol{A T}$ is referred to as $\boldsymbol{C P F C}$ (Fig.3). Hereinafter, a combined device DFSMC with a power of $200 \mathrm{MW}$ and an $\boldsymbol{A T}$ of $500 / 220 \mathrm{kV}$ with a power of 500 MVA with complex impedance of $60 \mathrm{Ohm}$ is considered. 
The change in the flow $P_{L}^{A}$ is carried out by regulating the active power flow through the DFSMC, $P_{y}$. In this case, the active power flowing through the $\boldsymbol{A T}$ is determined according to the expression $[32,36]$ :

$$
P_{A T}=P_{L}^{A}-P_{y} \text {. }
$$

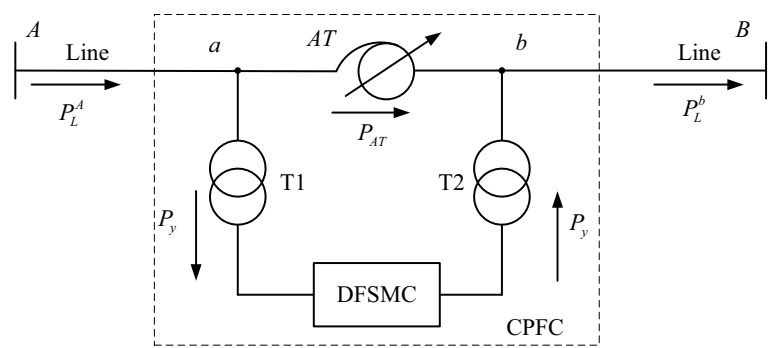

Fig.3. Principal scheme of an over-head-line $(\boldsymbol{O H L})$ with CPFC

If the active power flow $P_{y}$, passing through the DFSMC decreases, then the power flowing through the $\boldsymbol{O H L} P_{L}^{A}$ decreases as well. A decrease in the power $P_{L}^{A}$ flowing through the $\boldsymbol{O H L}$ also occurs with opposite direction of the flow $P_{y}$.

\section{CPFC to control a flexible interconnection and to increase its transmission capacity}

A schematic diagram of the studied inhomogeneous interconnection tie-line, containing parallel $\boldsymbol{O H L s}$ of 220 and $500 \mathrm{kV}$, connected at the intermediate substation through the $\boldsymbol{A T}$, is shown in Fig.5. It is correct to characterize such a connection as heterogeneous and meshed. With an increase in active power transmitted from one system to another, the power flow in $220 \mathrm{kV}$ $\boldsymbol{O H L}$ (lines 2 and 3) increases more rather than in 500 $\mathrm{kV} \boldsymbol{O H}$ (line 1). In this case, in certain operation modes, the transmission capacity limit of lines 2 and 3 can be reached, while the $500 \mathrm{kV}$ line 1 will remain underloaded. Therefore, there is a need to limit the power flow along $220 \mathrm{kV}$ lines depending on the operation mode in order to ensure the condition $P_{\text {OHL220 }} \leq P_{\text {limit }}$.

For simplicity reasons, when considering the principle of the $\boldsymbol{O H L}$ power flow control using the proposed device, the assumption is introduced that the voltage vectors $U_{A}$ and $U_{B}$ difference at the terminals of the $\boldsymbol{O H L}$ in points $A$ and $B$ of the power grid is constant (Fig.4), that is [36]:

$$
\delta_{A B}=\delta_{A a}+\delta_{a b}+\delta_{b B}=\text { const. }
$$

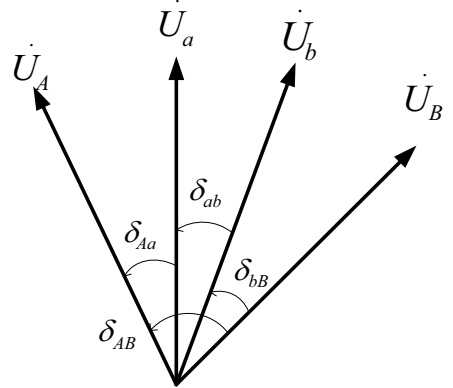

Fig.4. Vector diagram of the flexible transmission line

Due to the negligible values of power transmission sections' ohmic resistance, taking as an assumption that the voltage modules in points $a$ and $b$ are kept constant by regulating the output of synchronous machines' reactive power, it is fair to conclude that the transmitted active power along the sections $P_{L}^{A}$ and $P_{L}^{b}$ is determined by the angles between the voltage vectors $U_{A}$ and $U_{a}, U_{b}$ and $U_{B}$, that is, the angles $\delta_{A a}$ and $\delta_{b B}$ and the modules of these voltages:

$$
\begin{aligned}
& P_{L}^{A}=P_{\max }^{A} \sin \left(\delta_{A a}-\alpha_{A a}\right) ; \\
& P_{L}^{b}=P_{\max }^{b} \sin \left(\delta_{b B}-\alpha_{b B}\right),
\end{aligned}
$$

where $P_{\text {max }}^{A}, P_{\max }^{b}$ are the amplitude values of active power flowing in sections $A-a$ and $b-B$.

Within these assumptions, the active power through the $\boldsymbol{A T}$ is determined by the expression:

$$
P_{A T}=\frac{U_{a} U_{b}}{x_{A T}} \sin \delta_{a b} .
$$

Based on the expression (12), the angle between the voltages $U_{a}$ and $U_{b}$ results in:

$$
\delta_{a b}=\arcsin \frac{x_{A T} P_{A T}}{U_{a} U_{b}} .
$$

The analysis of the expressions in Eqs.(10)-(13) shows that at $P_{y}>0$ with a decrease in this power, the power $P_{A T}$ and the angle $\delta_{a b}$ increase. Then, according to Eq.(9), the angles $\delta_{A a}$ and $\delta_{b B}$, the active power in the transmission sections $P_{L}^{A}$ and $P_{L}^{b}$ and the power transmitted along the line $P_{L}$ decrease. By contrast, with increasing power $P_{\mathrm{y}}>0$ the described values increase as well.

An increase in the active power flow causes a voltage decrease at the substations, and in its turn, an increase in the reactive power flow leads to the line 2 electric current increase above the permissible value. The powerangle diagram of the combined device is shown, taking into account operation mode restrictions (for example, determined by the balance situation in the $\boldsymbol{P G}$ ).

To prevent the monitored lines' overloading, it is necessary to reduce the active power flow. As a result, maintaining of constant active power-flow mode transforms into maintaining a given value of electrical current in the transmission line under consideration.

Fig.6 shows that up to an active power flow of $200 \mathrm{MW}$ (section 1), no operation mode restrictions are required. At point 1, a specified power flow regulation is introduced up to the point 2 , determined by the need to maintain this power flow value following the balance situation in the electric power system. Within section 2- 
3, line 2 electric current limit violation occurs, caused by an increase in reactive power flow. In this case, it is necessary to reduce the transmitted active power below $P_{\text {L2_lim. }}$ With a further increase in the power transmitted through the power grid, an unacceptable voltage drop occurs at the adjacent grid's substations. To prevent this drop, the power flow along line 2 must be further reduced. In this case, the increase in active power flow through the grid decreases down to zero, after which the maximum allowed power flow continues to decrease.

Eventually, the control algorithm within the logic described in Eqs.(10)-(13) using $\boldsymbol{C P F C}$ allows to influence the power flow distribution, relieving the weak sections of the transmission grid. At the same time, this algorithm is efficient both for the example of the generalized system in Fig.3, and of the meshed grid presented in Fig.6.

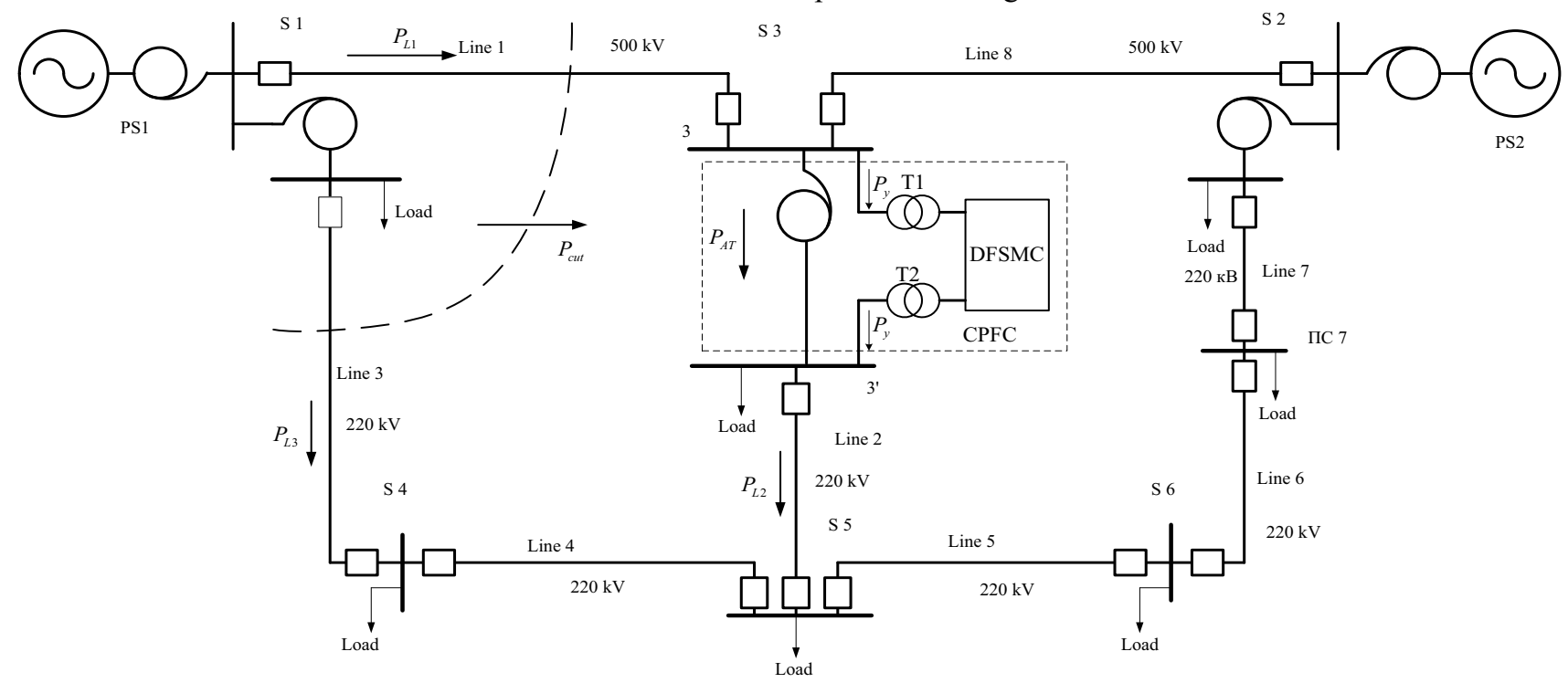

Fig.5. Principal scheme of the meshed grid with $\boldsymbol{C P F C}$

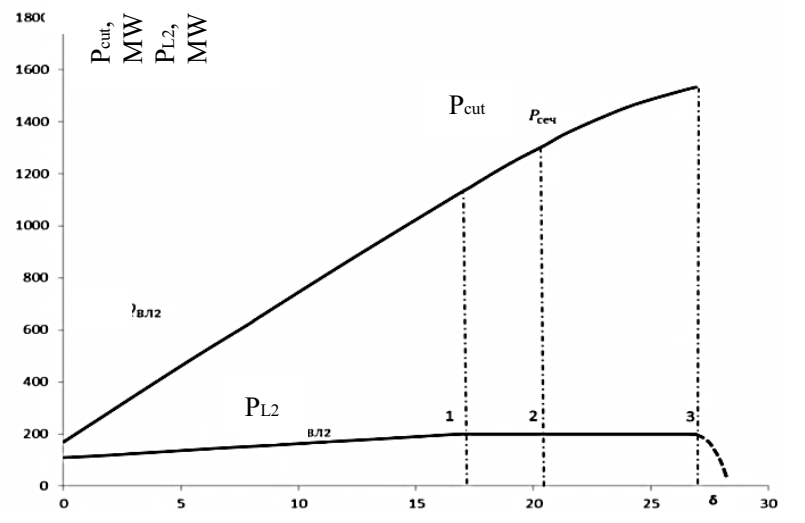

Fig.6. Power-angle diagram of the flexible with $\mathrm{CPFC}$

\section{Mathematical model of the meshed grid with CPFC to simulate transient processes}

Fig.7 shows a diagram of the testing meshed grid used to calculate electromechanical transients.

The power grid consists of transformers, autotransformers, power transmission lines and loads. The equations for these elements are written in the $d$ and $q$ coordinate system of the backbone machine.

The equations describing each $\boldsymbol{A S M}$ in the $d$ and $q$ axes $[18,25,31,32,39]$, result in: 


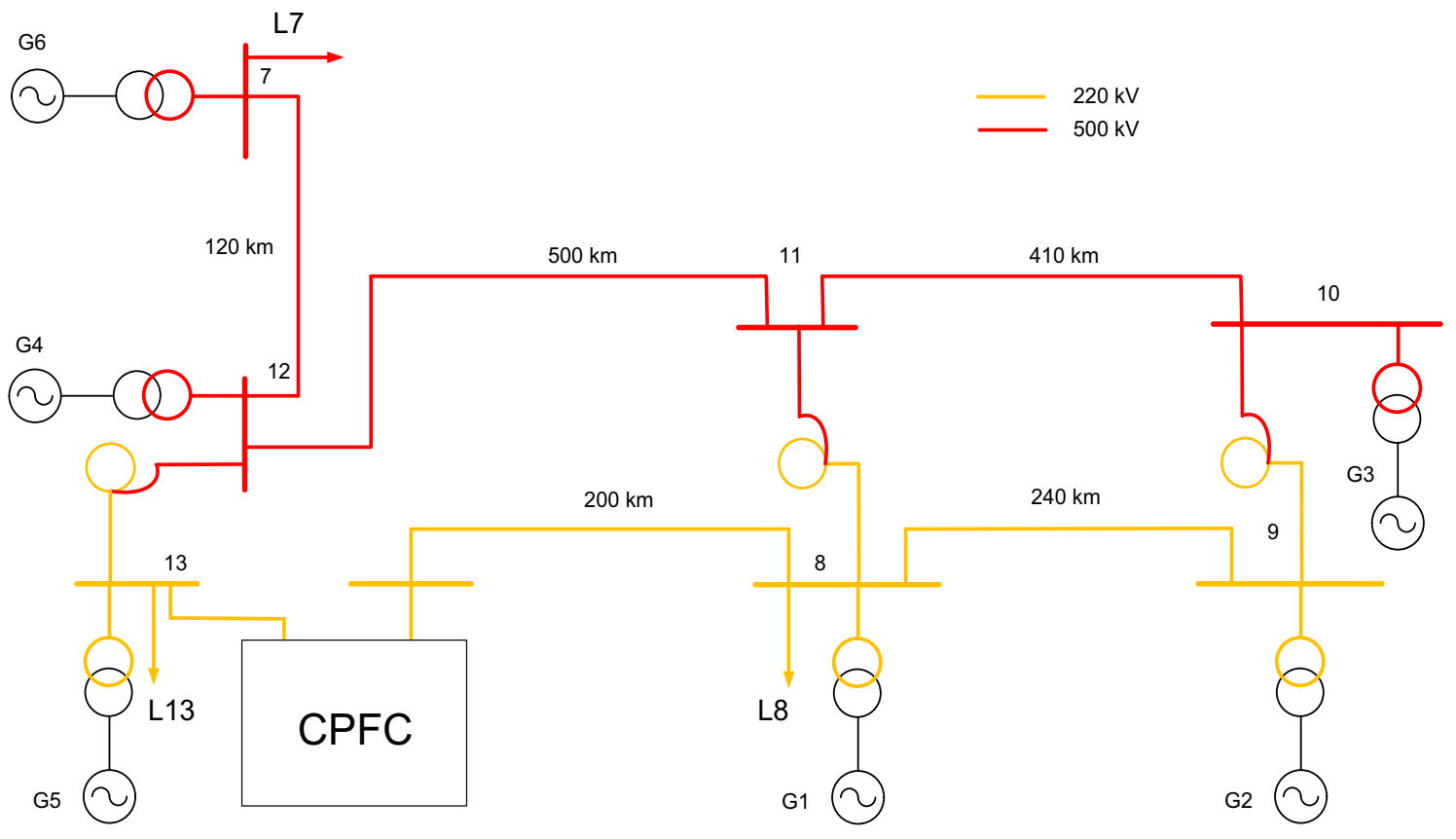

Fig.7. Grid model

$$
\begin{gathered}
U_{d}=\omega_{s}\left(E_{d}+i_{q} \cdot x_{q}\right), \\
U_{q}=\omega_{s}\left(E_{q}+i_{d} \cdot x_{d}\right), \\
p \cdot E_{d}^{\prime}=\frac{1}{T_{q 0 e q}}\left[E_{d e}-E_{d}\right]-s \cdot E_{q}^{\prime}, \\
p \cdot E_{q}^{\prime}=\frac{1}{T_{d 0 e q}}\left[E_{q e}-E_{q}\right]-s \cdot E_{d}^{\prime}, \\
p s=\frac{1}{T_{j}} \cdot\left(P_{e}-P_{T}\right),
\end{gathered}
$$

where $U_{d}$ and $U_{q}$ are the voltage vectors projections at the $\boldsymbol{A S M}$ connection points to the power system on the $d$ and $q$ axes; $s$ is the DFSMC shaft slip relative to the synchronous speed; $\omega_{s}$ is the synchronous rotation speed of the power grid; $E_{d}^{\prime}$ and $E_{q}^{\prime}$ are the transient $\boldsymbol{E M F s}$ along the $d$ and $q$ axes, respectively; $E_{d}$ and $E_{q}$ are the idle EMFs along the $d$ and $q$ axes, respectively; $i_{d}$ and $i_{q}$ are the machine stator currents along the $d$ and $q$ axes, respectively; $x_{d}$ and $x_{q}$ are synchronous inductive reactance along the $d$ and $q$ axes (an assumption is made about the magnetic symmetry of the $\boldsymbol{A S M}$ rotor, $x_{d}=$ $\left.x_{q}=x\right) ; P_{e}$ and $P_{T}$ are, respectively, the machine power output supplied to the grid, and the mechanical power on the machine shaft; $T_{d 0 e q}$ and $T_{q 0 e q}$ are rotor's circuit time constants; $T_{j}$ is rotor's inertia constant.

This equation system is a general case of a synchronous machine's mathematical model.

$\boldsymbol{A S M} \boldsymbol{G} 7$ and $\boldsymbol{G} \boldsymbol{8}$ are equipped with $\boldsymbol{A E C}$. The excitation is controlled by the voltage deviation at the generator terminals from the set value and its time derivative, the DFSMC shaft slippage deviation from the set value, and its time derivative, as well as by the deviation of the control power $P_{c}$ from the set value [25].

Forced $\boldsymbol{E M F}$ vector is decomposed in synchronous axes into $E_{q e}$ and $E_{d e}$ (Fig.8).
In the presented vector diagram, $\delta_{e}$ is the angle shift of the subsystem generators' rotors, relative to the synchronous axis, which is determined by the following expression:

$$
\delta_{e}=\frac{\sum_{i=1}^{N} T_{J i} \cdot \delta_{i}}{\sum_{i=1}^{N} T_{J i}},
$$

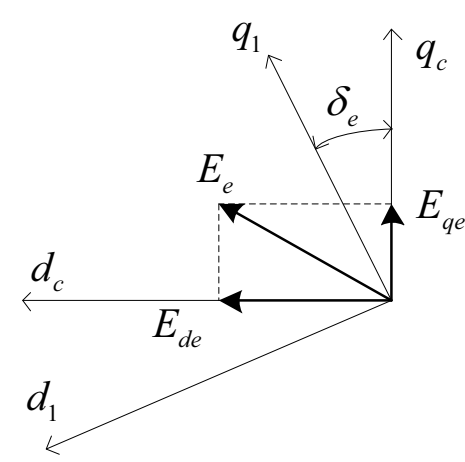

Fig.8. Forced EMF and its projections on axes $d$ and $q$

In Eq.(19), $N$ is the number of generators in the subsystem; $T_{J i}$ is the inertia constant of the $i$-th generator; $\delta_{i}$ is the rotor's shift angle of the $i$-th generator relative to the synchronous axis.

If the vector decomposition of the idle $\boldsymbol{E M F}$ in synchronous coordinates has the values $E_{q}$ and $E_{d}$, then, in the coordinates of the subsystem $\xi$, to which the $\boldsymbol{A S M}$ is connected, it would be $E_{q \xi}$ and $E_{d \xi}$, respectively (Fig.9). 


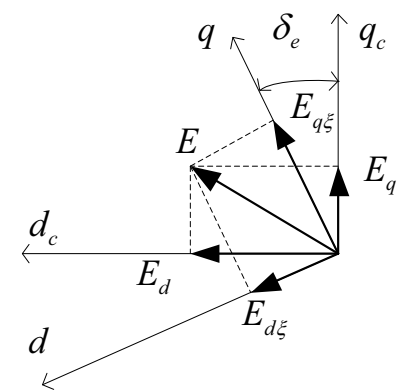

Fig.9. Idle EMF and its projections on axes $d$ and $q$

From Fig.9 the following formulas are obtained (separately for each subsystem) [25,39]:

$$
\left.\begin{array}{c}
E_{q \xi}=E_{q} \operatorname{Cos}\left(\delta_{e}\right)+E_{d} \operatorname{Sin}\left(\delta_{e}\right) \\
E_{d \xi}=-E_{q} \operatorname{Sin}\left(\delta_{e}\right)+E_{d} \operatorname{Cos}\left(\delta_{e}\right)
\end{array}\right\} .
$$

The $\boldsymbol{A S M}$ excitation regulation law in general (in the active power maintenance operation mode) is given by:

$$
\begin{gathered}
V_{y d \xi}=E_{d \xi 0}+V_{s}(\Delta s)+V_{P}(\Delta P), \\
V_{y q \xi}=E_{q \xi 0}+V_{U}(\Delta U),
\end{gathered}
$$

where $V_{S}$ is the control law for shaft slippage deviation; $\Delta s$ is the deviation of the shaft slip $s ; V_{P}$ is the control law for the deviation of the transmitted power; $\Delta P$ is the deviation of the transmitted power $P ; V_{U}$ is the control law for voltage deviation at the terminals of the combined device; $\Delta U$ is the deviation of the voltage $U$; $V_{y d \xi}$ and $V_{y q \xi}$ are the $\boldsymbol{A S M}$ excitation voltages in the projection on the $d, q$ axes, rotating at the machine rotor speed; $E_{d \xi_{0}}$ and $E_{q \xi_{0}}$ are the initial values of the idle $\boldsymbol{E M F}$ of $\boldsymbol{A S M}$ in the projection on the $d, q$ axes, rotating at the machine rotor speed.

Using (20)-(22) the reverse transition to synchronous axes is performed, taking into account the magnetic inertia of the rotor circuit:

$$
\left.\begin{array}{l}
E_{q e \xi}=\left(1+k_{f}\right)\left(\begin{array}{l}
V_{y q \xi} \operatorname{Cos}\left(\delta_{e \xi}\right)- \\
-V_{y d \xi} \operatorname{Sin}\left(\delta_{e \xi}\right)
\end{array}\right)-k_{f} E_{d \xi} \\
E_{d e \xi}=\left(1+k_{f}\right)\left(\begin{array}{c}
V_{y q \xi} \operatorname{Sin}\left(\delta_{e \xi}\right)- \\
-V_{y d \xi} \operatorname{Cos}\left(\delta_{e \xi}\right)
\end{array}\right)-k_{f} E_{q \xi}
\end{array}\right\},
$$

where $k_{f}$ is the ASM rotor current feedback factor.

A three-phase short circuit $(\boldsymbol{S C})$ at $500 \mathrm{kV}$ line in the deficient part of the power system (subsystem 1 ) in 0.3 seconds at node 12 (Fig.7) was considered as a normative disturbance. The generators' rotors angles, the rotational speed of the generators shafts, as well as the generators active power outputs were considered as comparative values. In Fig.10-Fig.15 the changes of the indicated values are presented for the generators $\boldsymbol{G} 4$ and $\boldsymbol{G} \boldsymbol{5}$ closest to the $\boldsymbol{S C}$ point.

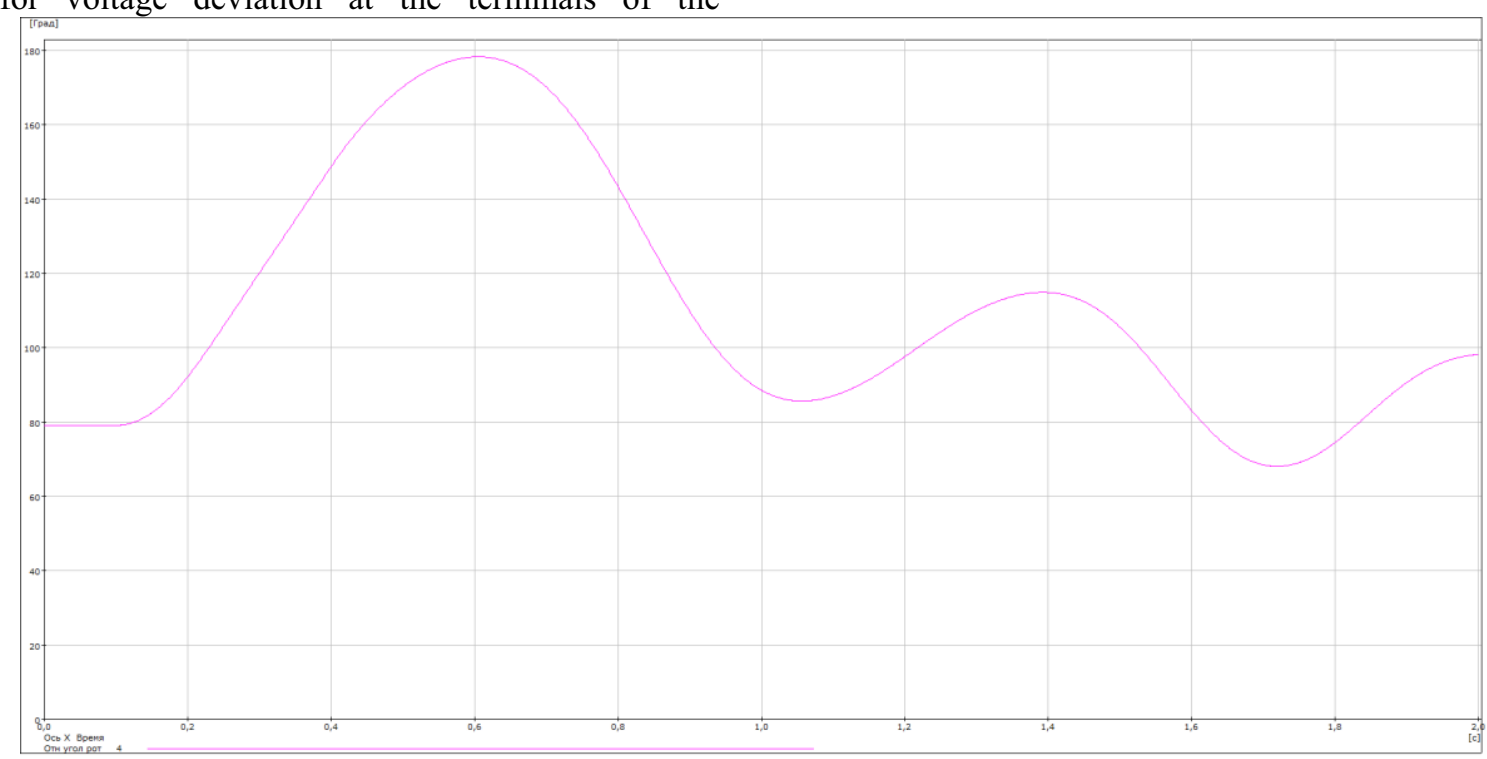

Fig.10. Rotor's angle of $G 4$ within 0.3 seconds $S C$ (developed software package)

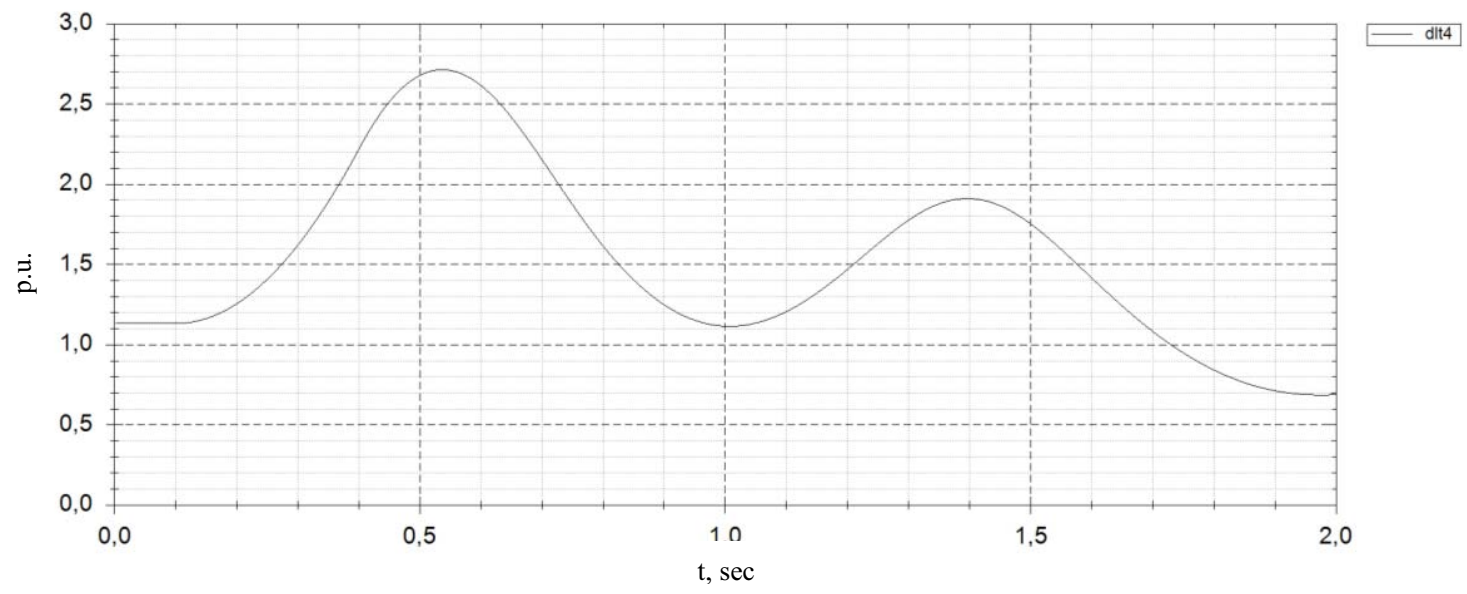

Fig.11. Rotor's angle of $G 4$ within 0.3 seconds $S C$ (software package Mustang) 


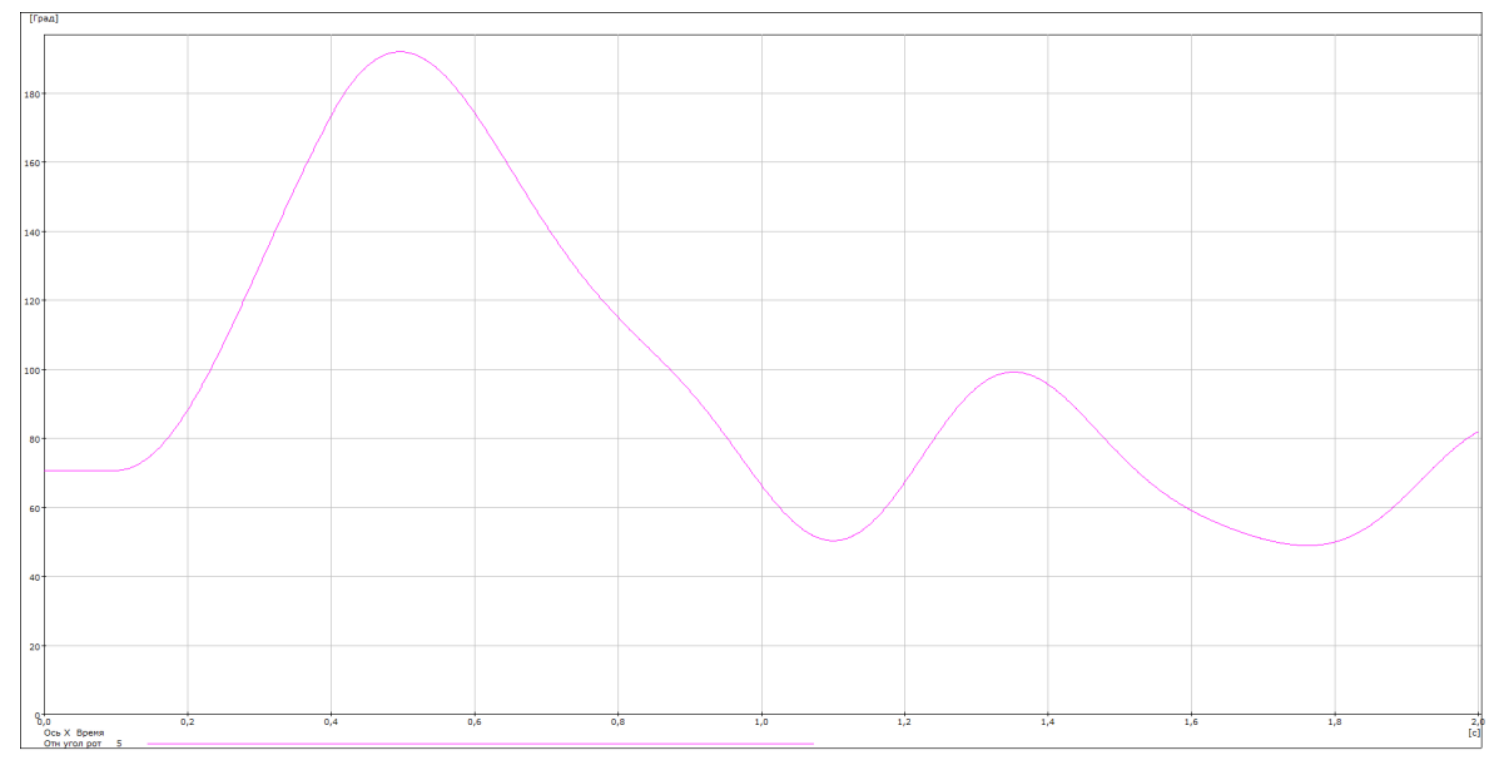

Fig.12. Rotor's angle of $G 5$ within 0.3 seconds $S C$ (software package Mustang)

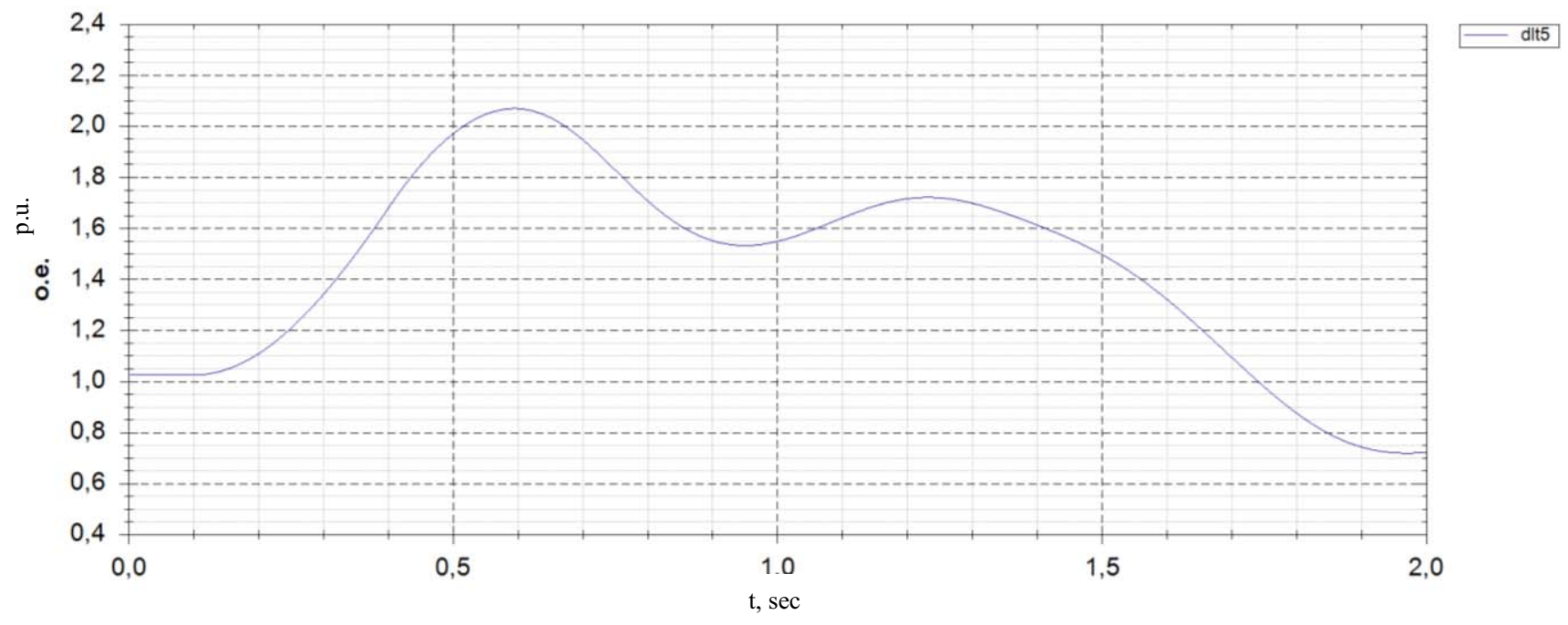

Fig.13. Rotor's angle of $G 5$ within 0.3 seconds $S C$ (developed software package)

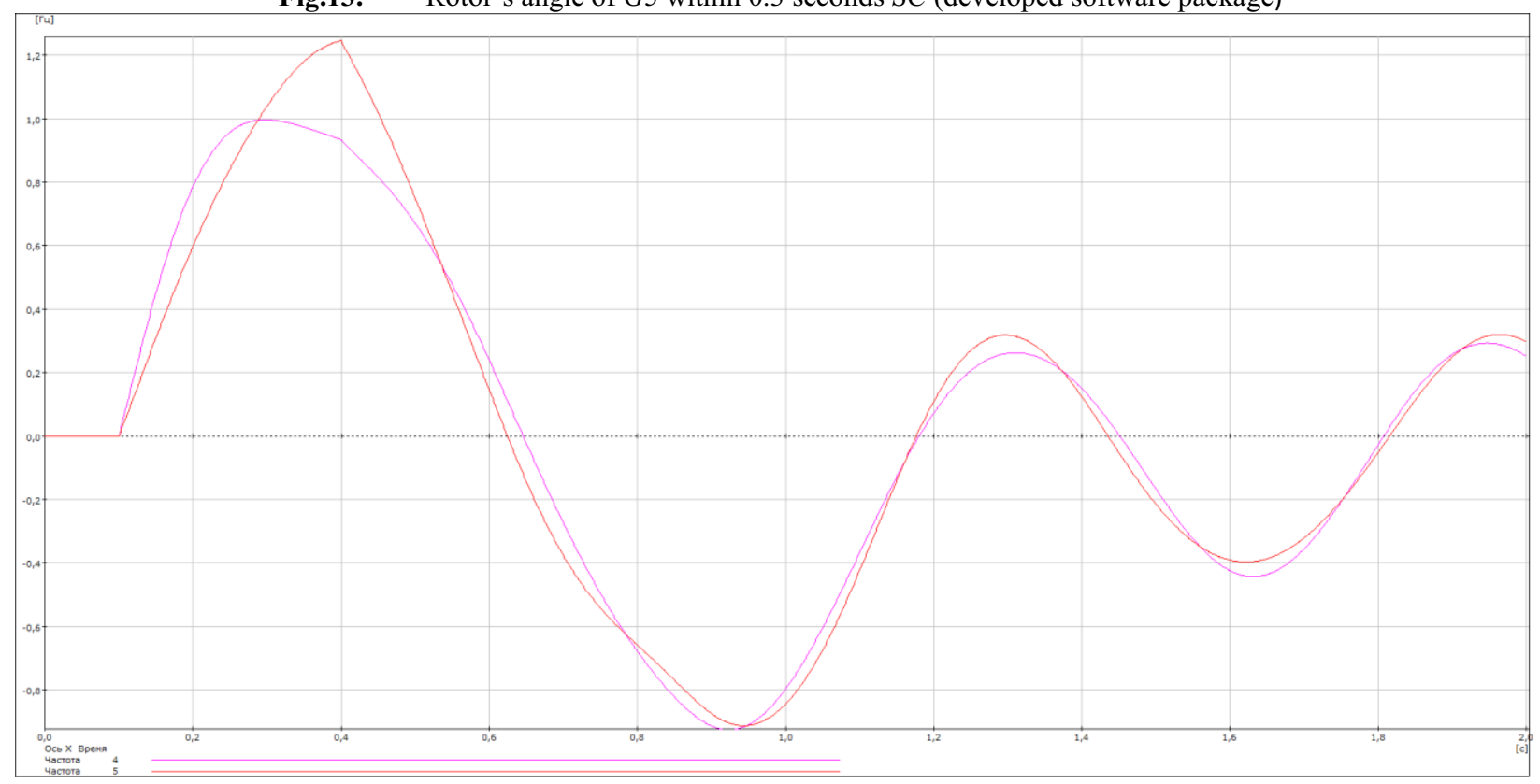

Fig.14. Rotor's angular frequency of $G 4$ and $G 5$ within 0.3 seconds SC (software package Mustang) 


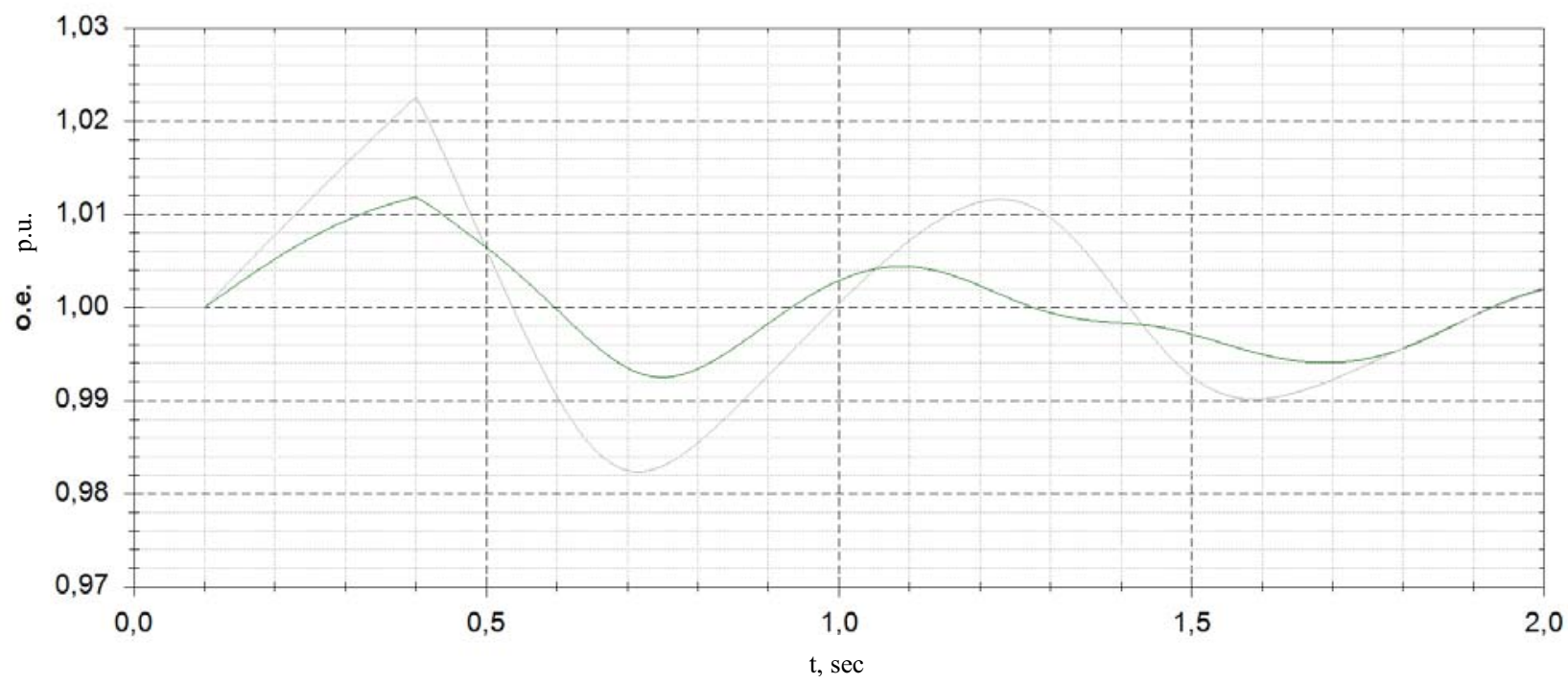

Fig.15. Rotor's angular frequency of G4 and G5 within 0.3 seconds SC (developed software package)

The simulation results showed a high reliability of steady-state and transient modes calculations in the developed software package in comparison with similar calculations in the industrial software package.

\section{Long-term dynamic processes in the grid with CPFC}

When considering long transient processes, the power network diagram shown in Fig.7 was used. A three-phase $\boldsymbol{S C}$ on the $500 \mathrm{kV}$ line was considered in the deficient part of the system (subsystem 1) in 0.3 seconds at node 12. Comparing the transient process graphs shows a decrease in the disturbance impact in the deficient part of the grid, separated from a $220 \mathrm{kV}$ grid by a combined device, on the surplus part of the $\boldsymbol{P S}$. Thus, he influence of the disturbance in one part of the grid is damped by the combined device. The difference in the values characterizing the transient process, excluding and including $\boldsymbol{C P F C}$, reaches $20-30 \%$.

In the power system's deficient part, the $\boldsymbol{C P F C}$ installation can significantly reduce the generator rotors' swing amplitude. There is a damping of the mode parameters oscillations and faster damping of the transient process than in the scenario without $\boldsymbol{C P F C}$.

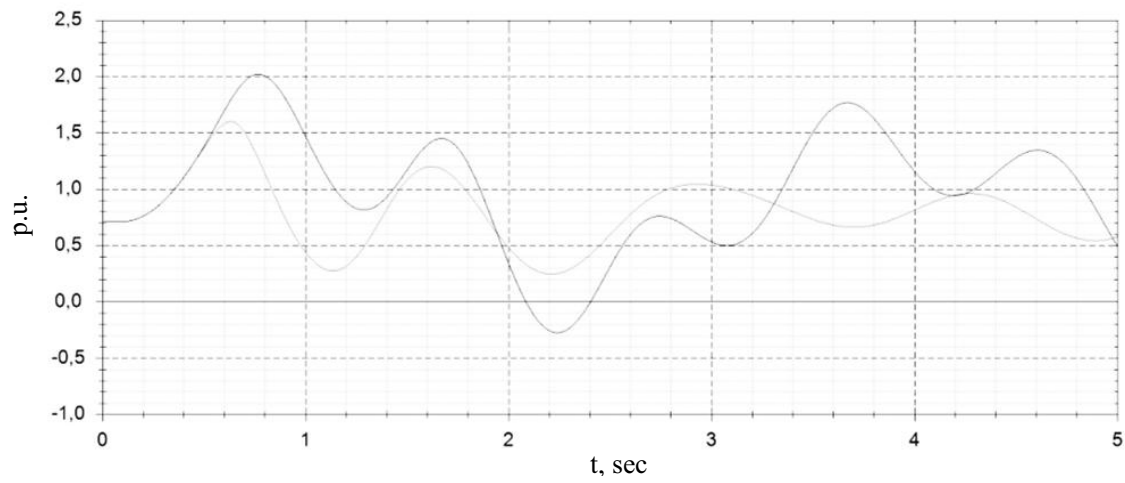

Fig.16. Rotor's angle of $G 6: 1$ - without CPFC; 2 - with CPFC

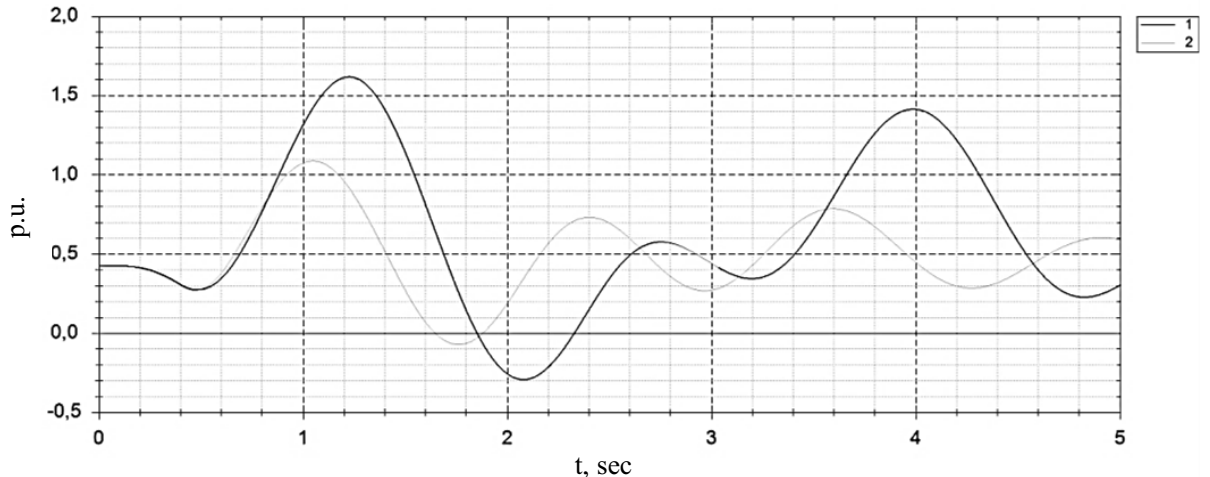

Fig.17. Rotor's angle of $G 2: 1$ - without CPFC; 2 - with CPFC 
The analysis of the transient processes graphs excluding and including the $\boldsymbol{C P F C}$ installation showed that the installation could significantly reduce the generator's mutual oscillations in both subsystems. The combined device installation allows increasing the power generators' stability in the power system by damping the oscillations and reducing the time of the transient process.

At the emergency failure or maintenance switching of the power transmission line at the interconnection ends, the intermediate substations' load should not be disconnected. The $\boldsymbol{C P F C}$ carries out its power supply.

Thus, of particular interest is the power grid's operation with the installed combined device when the load is supplied directly from it. In this case, the DFSMC task is to maintain a given voltage level at its terminals and a certain value of the active power flow (for clarity, only the parameter functions are shown, the control law of which is changed in the algorithm, also the $\boldsymbol{A E C}$ links inertia is not demonstrated). The excitation voltage is calculated as follows:

$$
\begin{gathered}
E_{d e 1}=E_{d e 01}+k_{0 \omega_{1}} \cdot\left(\omega_{r}-\omega_{r \text { set } 1}\right) \\
+k_{0 \omega_{1} d i f} \cdot \omega_{\text {dif }}, \\
E_{d e 2}=E_{d e 02}+k_{0 P} \cdot\left(P_{g}-P_{s e t}\right) \\
+k_{0 \omega_{2} \text { dif }} \cdot \omega_{d i f}
\end{gathered}
$$

where $\omega_{r}=s_{r}+1$ and $\omega_{r \text { set } 1}=\left(\omega_{1}+\omega_{2}\right) / 2$ are the actual and required rotation speed of the asynchronized electromechanical frequency converter shaft; $\omega_{\text {dif }}=$ $\omega_{1}-\omega_{2}$ is the frequency difference of the two subsystems; $k_{0 \omega_{1} \text { dif }}$ and $k_{0 \omega_{2} \text { dif }}$ are the gain factors for the frequency difference in subsystems 1, 2 (in the case under consideration, in the initial operation mode before the disturbance, the frequencies are equal, that is $\omega_{1}=$ $\left.\omega_{2}\right) ; k_{0 \omega_{1}}, k_{0 \omega_{2}}$ and $k_{0 P}$ are the gain factors for the frequencies deviation in subsystems 1,2 from the rated value and for the deviation of the actual transmitted power from the set value $P_{\text {set }}$, respectively; $P_{g}$ is the actual value of the transmitted active power.
When the $\boldsymbol{S C}$ is eliminated, the power supply of a load part is provided only by the $\boldsymbol{C P F C}$. After the $\boldsymbol{S C}$ elimination, the signal from the automatic line disconnection fixation is sent to the input of the $\boldsymbol{A E C}$ settings block of DFSMC machines. The fact that the line is disconnected leads to the shift of combined device operation mode from maintaining the given power flow to maintaining the rated frequency in the adjacent grid

$$
\begin{aligned}
E_{d e 1}=E_{d e 01}+ & k_{0 \omega_{1}}\left(\omega_{r 1}-\omega_{\text {set } 1}\right) \\
& +k_{0 \omega_{1} d i f} \cdot \omega_{d i f} \\
& +k_{\omega_{1}}^{D} \frac{d \Delta \omega_{r 1}}{d t} \\
E_{d e 2}=E_{d e 02}+ & k_{0 \omega_{2}}\left(\omega_{r 2}-\omega_{s e t 2}\right) \\
& +k_{0 \omega_{2} d i f} \cdot \omega_{d i f} \\
& +k_{\omega_{2}}^{D} \frac{d \Delta \omega_{r 2}}{d t}
\end{aligned}
$$

where $k_{\omega_{1}}^{D}$ and $k_{\omega_{2}}^{D}$ are the gain factors of the derivative of the DFSMC shaft rotation speed change for subsystems 1 and 2 .

A diagram of the grid under consideration with a detailed layout of the DFSMC connection point is presented in Fig. 18.

When the $\boldsymbol{A} \boldsymbol{T}$ is taken out for maintenance, the transmission of electric power by the combined device is carried out only by DFSMC machines.

The $S C$ was investigated on line 6-7 with its subsequent outage. At the same time, in the initial operation mode, the $\boldsymbol{M} 1$ machine, connected to node 6 of the scheme, operates in a motor mode, that is, it consumes active power from the grid. The $\boldsymbol{M} \mathbf{2}$ machine, in its turn, operates in a generator mode and provides active power to node 5 .

As a result of the $S C$ clearance on the line 6-7, the local load in node 6 is not disconnected and its power supply is carried out by the DFSMC. In this case, the DFSMC is automatically reversed: the $\boldsymbol{M} \mathbf{1}$ machine goes into the generator mode and the $\boldsymbol{M} \mathbf{2}$ - into the motor mode (Fig.19).

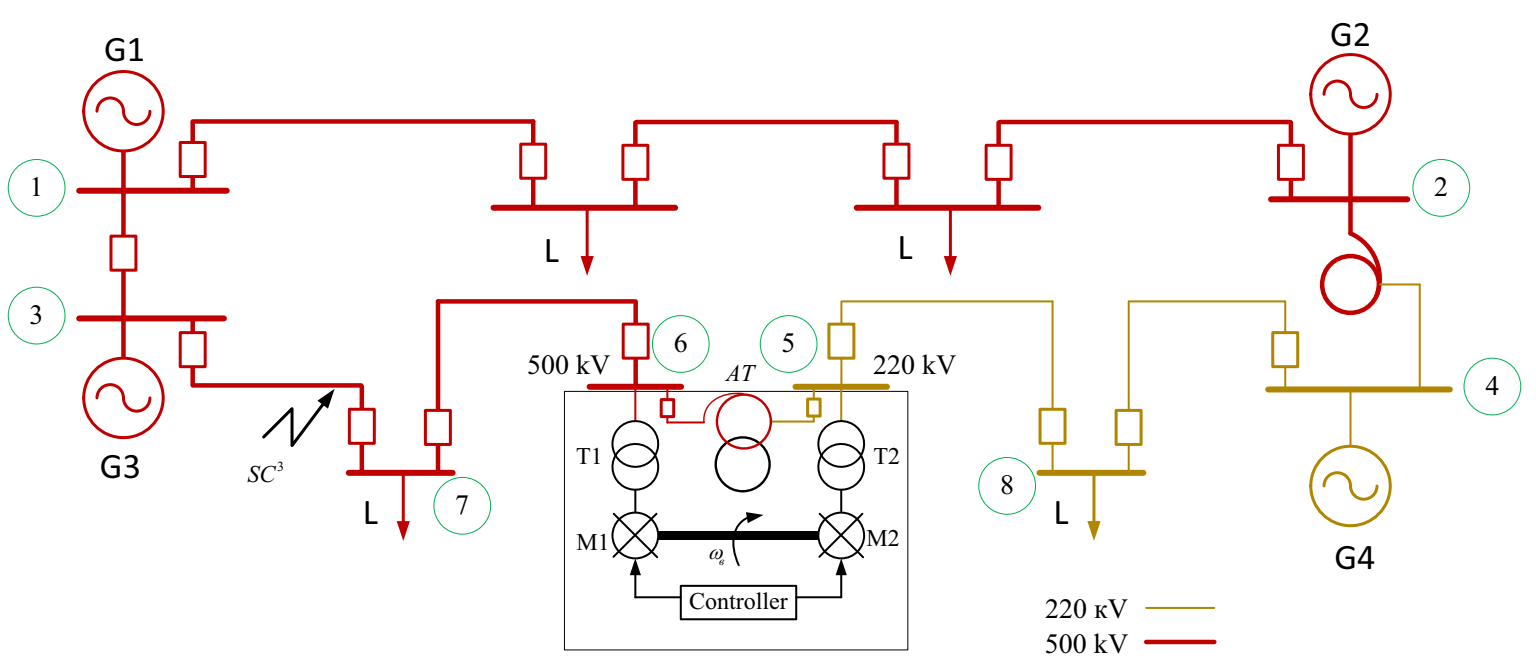

Fig.18. Principal scheme of the grid 


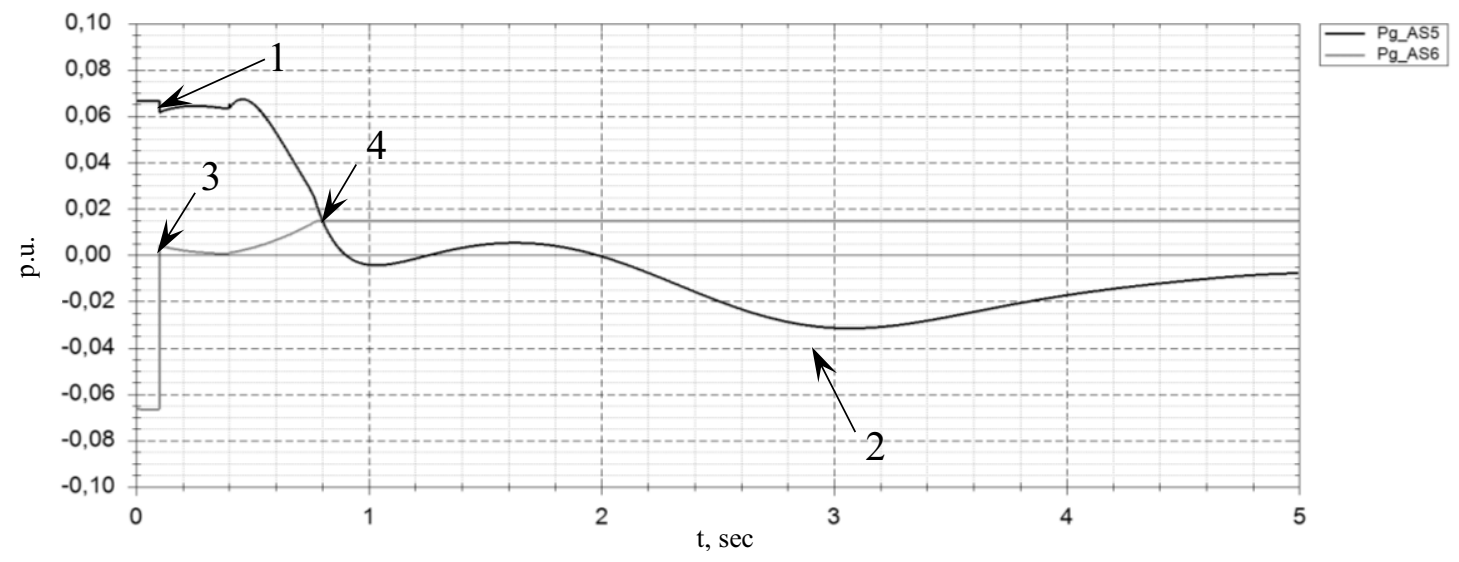

Fig.19. Active power of $M 1$ and $M 2$ within the long-term dynamic process

According to the calculations, the reverse of the DFSMC power is carried out in no more than 3 seconds, while the power supply to consumers from the $\boldsymbol{M I}$ machine is resumed in 0.4 seconds due to the asynchronized machine's rotors kinetic energy. It should be noted that the frequency in the adjacent grid does not change significantly and does not go beyond the operation settings of the existing automation devices.

Thus, the performed calculations proved the high efficiency of using the combined device in terms of improving the transient electromechanical processes quality, and also made it possible to form an algorithm for controlling DFSMC machines in the case of its isolation to a balanced power region without deteriorating the power supply quality to consumers.

\section{References}

1. Dorofeev V.V., Makarov A.A. Active-adaptive grid a new quality of the UES of Russia - Energoexpert, 2009, 4, http://energyexpert.ru (in Russian)

2. Shakaryan Yu.G., Novikov N.L. Technological platform SMART GRID (fixed assets) Energoexpert, 2010, No. 4, http://energyexpert.ru (in Russian).

3. Shakaryan Yu.G., Novikov N.L., Novikov A.N. Devices of controlled (flexible) AC power transmission systems (FACTS) and recommendations for their application in the electric power systems of Russia (in Russian).

4. Suprunov I.S., Likhachev A.P., Dvorkin D.V. Asynchronized electromechanical frequency converter implementation for limiting short-circuit currents on the example of a metropolitan city. Publications of laureates of the international competition of scientific, scientific and technical and innovative developments for the development of the fuel, energy and mining industry. - M .: Ministry of Energy of the Russian Federation, Development Technologies LLC, 2020, pp. 36-41 (in Russian).

5. Dementyev Yu.A., Sokur P.V., Shakaryan Yu.G., Mayorov A.V., Shabash A.M., Yarosh D.N., Pinchuk N.D., Tretyakov V.S. Electromechanical AC insert for modes control and short-circuit currents limitation. Energy of the unified power grid, 2017, No. 4 (33), pp. 18-27 (in Russian).

6. Volkov E.P., Barinov V.A. On the creation of a 220 $\mathrm{kV}$ electrical coupling between the IPS of Siberia and the IPS of the East - Energetik, 2008, No. 5, pp. 2-8 (in Russian).

7. Chistyakov V.N. Smart Grid - Business Navigator. Supplement to the all-Russian newspaper "Energetics", 2010, June, Media Center, pp. 2 - 3, after www.energogazeta.ru (in Russian).

8. Zelenokhat N.I., Sharov Yu.V. New technological solutions to the implementing joint operation of power grids of the East and West - Electricity, 2007, No. 9, pp. 34-40 (in Russian).

9. Zelenokhat N.I., Sharov Yu.V. Combined integration of large power systems - Electricity, 2006, No. 5, pp. 2-10 (in Russian).

10. Zelenokhat N.I., Sharov Yu.V., Denisov D.I. Quasicontrolled interstate electrical connections and their operating properties - New in the Russian electric power industry, 2005, No. 10, pp. 4-12 (in Russian).

11. Shakaryan Yu.G. Controlled (flexible) AC transmission systems. Access mode: http://fskees.ru/common/img/uploaded/managed_systems.pdf (in Russian).

12. Study guide "Intersystem connection with controlled operating characteristics" Zelenokhat N.I., Vlasova T.A. 2003 - 58 p (in Russian).

13. Burman A.P., Rozanov Yu.K., Shakaryan Yu.G. Prospects for the application of flexible (controlled) AC transmission systems in the UES of Russia Electrical Engineering, 2004, No. 8, pp. $30-37$ (in Russian).

14. Dorofeev V.V., Shakaryan Yu.G., Kochkin V.I., Koshcheev L.A., Khvoshchinskaya Z.G. Prospects for the application of flexible (controlled) AC power transmission systems in the UES of Russia - Power plants, 2004, No. 8, pp. 10-13 (in Russian).

15. Shakaryan Yu. G., Labunets I.A., Plotnikova T.V., Sokur P.V. et al. Development and prospects for the application of new types of turbogenerators with a 
vector excitation control system - Electrical Engineering, 2010, No. 2, pp. 4a-9 (in Russian).

16. Dyakov A.F., Zelenokhat N.I. New approaches to solving the joint operation of the UES of Russia with the energy systems of other countries. Bulletin of the Academy of Electrotechnical Sciences of the Russian Federation, No. 2, 2009, pp. 1-10 (in Russian).

17.Zelenokhat O.N., Aristov I.S., Mikryukov D.Yu., Shakhov V.O. Management of power flows through intersystem connections in stationary modes using new technologies - Power Engineer, 2012, No. 6, pp. 43-45 (in Russian).

18. Zelenokhat N.I. Static stability of flexible intersystem communication. Bulletin of Moscow Power Engineering Institute, 1996, No. 4, pp. 32-38 (in Russian).

19. Zelenokhat N.I. Operating characteristics analysis of the intersystem communication with static compensators - Electricity, 1997, No. 3, pp. 13-18 (in Russian).

20. Kirschner L., Retzmann D., Thumm G. Benefits of FACTS for Power System Enhancement // IEEE/PES Transmission and Distribution Conference and Exhibition: Asia and Pacific. - 2005. - pp. 88-98.

21. Paserba J. How FACTS Controllers Benefit AC Transmission Systems // IEEE PES General Meeting Panel Session on FACTS Fundamentals. - Denver, Colorado. - 2004. - pp. 320-325.

22. Baldick R., Kahn E. Contract paths, phase shifters, and efficient electricity trade // IEEE Trans. on Power Systems. - 1999 - vol. 12, no. 2, pp. 749-755.

23. Sood V. HVDC and FACTS Controllers. Applications of Static Converters in Power Systems / V. K. Sood. - Boston: Kluwer Academic Publishers, 2004. - $245 \mathrm{p}$.

24. Kochkin V.I., Shakaryan Yu.G. Operating modes of the controlled power transmission lines. Electricity, 1997, No. 9, pp. 2-8 (in Russian).

25. Zelenokhat N.I. Improving the efficiency of control the modes of flexible intersystem connection with electromechanical d.c. link - Bulletin of Moscow Power Engineering Institute, 2005, No. 3, pp. 66-73 (in Russian).

26. Zelenokhat N.I. The problem of the power exchange between the power interconnections of the East and West and the hybrid approach principle to its solution - Electro, 2004, No. 2, pp. 2-5 (in Russian).

27. V.A. Venikov, N.I. Zelenokhat, Yu G. Shakaryan et al. On the use of electromechanical frequency converters in power systems - Electricity, 1977, No. 4, pp. 10-14 (in Russian).

28. Venikov V.A., Zelenokhat N.I., Shakaryan Y.G. and Sukhanov L.A. Application of Digital Computers to the' Study of Power Systems with Asynchronized Electromechanical Frequency Converters - Electrical Power \&Power Systems, Vol. 1, № 2, pp 113-117, July 1979, New York.
29. Zelenokhat N.I., Makeyechev V.A., Vlasova T.A. Dynamic Characteristics of Electromagnetically Sectionalized Electrical" Station - CIGRE, Symposium, London, June 1999.

30. Zelenokhat N.I. The problem of creating controlled intersystem connections with asynchronized electromechanical frequency converter - Bulletin of Moscow Power Engineering Institute, 1995, No. pp. 97-100 (in Russian).

31. Zelenokhat N.I. Improving the management efficiency of flexible intersystem communication with electromechanical d.c. link. Bulletin of Moscow Power Engineering Institute, 2005, No. 3, pp. 66-73 (in Russian)

32. Zelenokhat N.I., Zelenokhat O.N., Aristov I.S., Mikryukov D.Yu. Analysis of static stability of intersystem connection with a power flow control device - Power Engineer, 2012, No. 6, pp. 43-45 (in Russian)

33. Shakaryan Yu.G. Asynchronized synchronous machines. Options of an autonomous generator according to the double-feed machine scheme with various types of frequency converters. Access mode: http://www.elecab.ru/obzor1-1.htm (in Russian).

34. Shakaryan Yu.G., Bobylev A.V. New power equipment of the XXI century. Access mode: http://www.rao-ees.elektra.ru/ru/news/gazeta/1512004/show.cgi?novo.htm (in Russian).

35. Glebov I.A., Sukhanov L.A., Safiullina R.Kh. Electromechanical frequency converters for communication of electric power systems - News of the USSR Academy of Sciences. Energy and transport, 1977, No. 6, pp. 49-57 (in Russian).

36. Zelenokhat N.I. Intellectualization of the UES of Russia: innovative proposals: a practical guide. - M .: Publishing house of Moscow Power Engineering Institute, 2013,192 p (in Russian).

37. Kochkin VI, Shakaryan Yu. G. Application of flexible (controlled) AC power transmission systems in power systems. - M .: TORUS PRESS, 2011 - 312 $\mathrm{p}$ (in Russian).

38. FACTS - improving the quality of power grids Access mode: http://www.abb.ru/cawp/ruabb056/f4681e116b81284 6c1256da40043bb4f.aspx (in Russian).

39. Shakaryan Yu.G. Asynchronized synchronous machines. - M .: Energoatomizdat, 1984 .- 193 p (in Russian).

40. Merkuryev G.V., Shargin Yu.M. Stability of power systems. Calculations Monograph. SPb.: Non-state educational establishment "Energy Personnel Training Center", 2006. - 300p (in Russian).

41. V.V. Ezhkov, N.I. Zelenokhat, I.V. Litkens et al. Transient processes of electrical systems in examples and illustrations: Study guide for universities. - Eds. V.A. Stroeva. - M .: Znak, 1996. - 223 p (in Russian). 
42. RUSTAB user manual Vladimir Neuymin, Vladimir Ivanov and others. TechSystem Group. 2009, 93 p (in Russian).

43. Mamikonyants L.G. Aspects analysis of transient and asynchronous modes of synchronous and asynchronous machines. Eds. Shakaryan Yu.G. - M .: ELEKS-KM, 2006, 368 p (in Russian).

44. Peter Van Meirhaeghe. Double fed induction machine: a EUROSTAG model. Tractebel Engineering. 2004.M. Ben Rabha, M.F. Boujmil, M. Saadoun, B. Bessaïs, Eur. Phys. J. Appl. Phys. 